\title{
CONSTITUCIONALISMO E TRIBUTAÇÃO
}

\begin{abstract}
Ricardo Ferreira Sacco *
Resumo: O objetivo deste artigo é analisar da principal causa que levou ao descontentamento e quebra da ordem legal na América Inglesa nos fins do século XVIII: o aumento abusivo da carga tributária. Busca-se promover um estudo das circunstâncias que levaram à Revolução Americana de 1775 e ao nascimento do constitucionalismo moderno. Utilizou-se a revisão bibliográfica como fonte de pesquisa indireta, assim como textos históricos traduzidos pelo autor como fontes diretas. O objetivo principal dos colonos americanos foi rejeitar a interferência abusiva sob a forma de tributação, culminando o processo no nascimento do constitucionalismo moderno, também chamado de constitucionalismo escrito.

Palavras-chave: Constitucionalismo moderno; Constituição; Tributação; Limitação do Estado; Guerra Revolucionária
\end{abstract}

\section{CONSTITUTIONALISM AND TAXATION}

Abstract: The purpose of this article is to analyze the main cause that generated discontent and the violation of the legal order in English America in the late 18th century: the abusive increase in the tax burden. It promotes a study of the circumstances that led to the American Revolution and the birth of modern constitutionalism. Bibliographic review was used as a source of indirect research, as well as historical texts as direct sources. The main objective of American colonists was to reject abusive interference in the form of taxation, culminating the process in the birth of modern constitutionalism.

Keywords: Modern constitutionalism; Constitution; Taxation; State limitation; Revolutionary War

\section{INTRODUÇÃO}


Busca-se neste artigo uma análise da principal causa que levou a um movimento conflituoso, - ao descontentamento e à quebra da ordem legal na América Inglesa nos fins do século XVIII, conhecido como Revolução Americana de 1775 e que acabou por desencadear posteriormente um processo de elaboração de constituições escritas. Pode-se considerar como o estopim deste processo o aumento abusivo da carga tributária que ultrapassou o sentimento cristalizado no homem comum como aquele que seria o limite aceitável da interferência estatal em suas vidas.

Havia se cristalizado na América do Norte uma autonomia política significativa e uma mentalidade ligada aos princípios consagrados pela política inglesa após a Revolução Inglesa de 1688 e do Bill of Rigths de 1689, influenciados pelo pensamento político de John Locke (DALLARI, 1998).

O Bill of Rigths previa o Parlamento como responsável por legislar, instituir tributos, manutenção de um exército permanente, dentre outros. Na verdade, por ser o produto de um processo histórico longo, o modelo inglês estava tão arraigado na cultura popular que pôde prescindir até mesmo de uma constituição escrita (BARROSO, 2009).

Muitas transformações sociais desencadearam o constitucionalismo na América Inglesa no final do século XVIII e as repercussões desse movimento trouxeram reflexos ao desenvolvimento das instituições jurídico-políticas do mundo ocidental moderno. A tributação representava nos últimos dez anos o grande incômodo na vida daqueles colonos. Eclodido o movimento, objetivo principal era a rejeitar uma interferência abusiva sob a forma de tributação e, em seguida, a criação de meios para a sociedade se proteger do avanço sobre o que representava a liberdade natural (BARROSO, 2009).

Têm-se claro que nenhum fenômeno jurídico e social surge espontaneamente e para se compreender algo presente, necessário se faz conhecer as origens e desenvolvimento dos fatos, ideias e teorias presentes em sua época. O pesquisador deve seguir desde as suas origens as pistas do conhecimento científico a que se propõe pesquisar; rever paradigmas, estudar sua evolução e processos de mudança (KUHN, 2000). Utilizou-se a revisão bibliográfica como fonte de pesquisa indireta, assim como textos históricos traduzidos pelo autor como fontes diretas. 
A análise do pensamento que levou à criação de limites à atuação do Estado na esfera individual e levou o mundo ocidental ao constitucionalismo moderno ocorreu através da combinação de fatores político-culturais neste momento histórico. Tal processo não se deu em um contexto isolado, mas em um contexto social complexo e multifacetado, no qual a sociedade buscava mecanismos de garantia, proteção e controle, culminando tal processo com nascimento do Constitucionalismo a partir de 1776 (BARROSO, 2009).

\section{A MUDANÇA QUE ALTEROU AS INSTITUIÇÕES POLÍTICAS}

O constitucionalismo moderno surgiu na América Inglesa (1776) e, passados alguns anos, na França (1791), após a Revolução de 1789, havendo inspirações teóricas comuns, como Locke, Rousseau e Montesquieu, contudo, seguindo caminhos próprios e individuais, mas a influência dos primeiros textos constitucionais norte- americanos é evidente:

Com a assinatura da aliança entre a França e os Estados Unidos em 1778, esses
textos constitucionais dos Estados, que passaram a ser conhecidos como Code de la
Nature, foram publicados em Paris. Em 1783, o ministro dos EUA em Paris,
Benjamin Franklin, obteve do ministro francês de Relações Exteriores uma
autorização oficial para a impressão em Paris das Constitutions des Treize Etats de
l'Amerique. Em 1786, um ano antes da elaboração da Constituição dos EUA, o
filósofo e matemático francês Marquês de Condocet, ao sintetizar suas ideias para a
formulação de uma declaração francesa de direitos, realizou um estudo sobre o papel
das ideias políticas norte-americanas intitulado De l'influence de la Revolution
d'Amerique sur l'opinion et la legislation de l'Europe (BLAUSTEIN, 2004).

O Constitucionalismo na América Inglesa representou uma mudança paradigmática que alterou sobremaneira as instituições jurídicas no mundo moderno. A compreensão dos objetivos que nortearam a criação destes documentos constitucionais mostra o aparecimento do poder social como um vínculo que une o povo a um fim comum, bem como a criação de obstáculos a quem tentasse alterar ou mitigar o exercício deste poder pelo seu titular, qual seja, o povo (FROTHINGHAM, 1916).

É possível verificar historiadores apontarem o nascimento do Constitucionalismo na França pós-revolucionária, relegando para segundo plano, ou simplesmente se esquecendo do que ocorrera na América Inglesa que, inclusive, exerceu influência indireta no próprio movimento francês (BLAUSTEIN, 2004). Tem-se que a primeira Constituição Francesa, datada de 1791, não durou um ano sequer, ao passo que a norte americana está em vigor até 
os dias de hoje. Há que se ressaltar, com relação à Constituição Francesa, que não se pode deixar de mencionar sua importância no que se refere à "vocação universalista de difusão de ideias que lhe está associada" (MIRANDA, 2003, p. 161). Fato é que foi na América que um movimento político-social trouxe complexas e profundas mudanças na estrutura do Estado.

O Constitucionalismo moderno trouxe em seu conteúdo a fonte geradora e disciplinadora do poder social, qual seja, a Constituição do Estado, fixando seus limites de atuação e distribuindo competências, sendo a própria manifestação do poder social.

A sociedade organizada por um vínculo cria o Estado no qual se insere e do qual ela é parte integrante (DALLARI, 1998). O referido vínculo seria a Constituição do Estado. A abordagem histórica, que compõe parte do estudo aqui apresentado, é imprescindível e tem-se aqui o objetivo de se observar esse "conjunto de ilustrações recorrentes" que a história nos mostra a fim de se desenhar o contexto histórico deste fenômeno (KUHN, 2000, p. 67).

Será abordada aqui a evolução de uma comunidade que, na prática, inaugurou essa ideia de poder partindo do corpo social - Commonwealth ${ }^{1}$ (FROTHINGHAM, 1916), - que criou uma "Constituição da Comunidade" - e em que circunstâncias essa ideia inovadora até então se desenvolveu. Seria na verdade uma forma de se estabelecer vínculos com o pensamento que inaugurou um novo paradigma (KUHN, 2000) de Constituição no século XVIII, ainda que primitiva ao observador preso ao paradigma moderno, mas que reflete a semente do que seria hoje a evolução do controle social e a limitação ao poder de tributar.

Quando se discute Constitucionalismo, também pensamos na proteção do indivíduo diante do próprio Estado. Em sua versão original, a Constituição Americana "não possuía uma declaração de direitos, que só foi introduzida em 1791, com as primeiras dez emendas, conhecidas como Bill of Rights" (BARROSO, 2009, p.18).

Para se ter uma ideia, a título comparativo, enquanto as dez primeiras emendas à Constituição Americana estavam sendo promulgadas, pode-se citar a França, que costuma ser apresentada como referência no estabelecimento de direitos individuais, que proibia formalmente as associações através da Lei Le Chapellier de 1791. Tal lei estabeleceu a

\footnotetext{
${ }^{1}$ Em um conceito jurídico-político, "Commonwealth", além da noção de comunidade, também teria embutido neste conceito um sentido de corpo social, e um corpo social autônomo para gerir seus próprios interesses. É utilizado por vezes como sinônimo de república (FROTHINGHAM, 1916).
} 
interdiction formelle de s'associer, para, somente a partir de 1901, garantir a liberdade de associação revogando a referida lei (MANCUSO, 2004, p.72).

$\mathrm{Na}$ verdade, o primeiro conjunto de normas com hierarquia superior que visava a criação de uma entidade governamental e política na América foi a chamada Fundamental Orders of Connecticut de 1639, contudo, a Constituição da Virgínia de 1776 foi a primeira a usar a palavra "Constituição" (BLAUSTEIN, 2004).

Em qual contexto histórico-político nasceu o pensamento de se criar um corpo de leis superiores que regulasse a relação entre Estado e sociedade? Para se responder a essas questões será necessária uma breve viagem histórica ao século XVII.

\subsection{A LIMITAÇÃO DO PODER ESTATAL}

A Magna Charta Libertatum foi um marco simbólico da história constitucional; "uma semente". Originalmente foi apenas um documento que resguardava direitos feudais dos barões com relação à propriedade, tributação e liberdades, incluindo a religiosa. “A amplitude de seus termos, todavia, permitiu que, ao longo do tempo, assumisse o caráter de uma carta geral de liberdades públicas" (BARROSO, 2009, p.10).

Em 1688 a Revolução Inglesa abriu espaço para, em 1689, o Parlamento aprovar o Bill of Rigths, agora influenciado pelo pensamento político de John Locke. A Carta de Direitos passou a estabelecer limites ao poder do monarca e contribuiu para a afirmação dos direitos naturais (DALLARI, 1998).

O Bill of Rigths previa a convocação regular do Parlamento, responsável pela criação de leis, instituição de tributos, autorização para a manutenção de um exército permanente em tempos de paz; estabeleceu imunidades aos parlamentares em razão de suas manifestações, dentre outras. Na verdade, por ser "fruto de um longo amadurecimento histórico, o modelo Inglês estabeleceu-se sobre raízes tão profundas que pôde prescindir até mesmo de uma constituição escrita". Dentre outros documentos, merecem destaque a Petition of Rights (1628), a Bill of Rights (1689) e o Act of Settlement (1701) (BARROSO, 2009, p.12).

Os ideais do liberalismo em Locke, sobretudo na obra intitulada Segundo Tratado Sobre o Governo Civil, foram fundamentais: "a liberdade dos homens submetidos a um 
governo consiste em possuir uma regra permanente à qual deve obedecer, comum a todos os membros daquela sociedade e instituída pelo poder legislativo nela estabelecido" (LOCKE, 1978, p.41). E continua:

o ponto de partida e a verdadeira constituição de qualquer sociedade política não é nada mais que o consentimento de um número qualquer de homens livres, cuja maioria é capaz de se unir e se incorporar em tal sociedade. Esta é a única origem possível de todos os governos legais do mundo (LOCKE, 1978, p. 62).

John Locke, que ficou conhecido como "pai do liberalismo", muito produziu e seus escritos trataram de temas sensíveis como tolerância religiosa, educação e política, o que lhe concedeu fama e influência na Europa. Locke foi um dos mais importantes precursores do Iluminismo europeu e fundador do empirismo inglês, sendo que seu pensamento é um clássico da tradição filosófica-política (TERUYA; GOMES; LUZ; CARVALHO, 2010).

O liberalismo e a crença na liberdade nos campos da moral, religião e política, representavam uma mudança de paradigma na Europa, e a América Inglesa do final do século XVIII ofereceu campo fértil para essas novas ideias, especialmente obras de mais dois filósofos políticos que muito influenciaram o pensamento de sua época: Jean Jacques Rousseau e Charles Luiz Montesquieu.

A obra "Do contrato social" de Rousseau, escrita em 1762 exerceu influência imediata. O contratualismo trouxe nova dimensão à sociedade, quando pregava a alienação de direitos individuais em favor da comunidade. Entende que "a ordem social é um direito sagrado que serve de base a todos os outros", não encontrando seu fundamento na natureza, mas sim nas convenções (ROUSSEAU, 1999, p. 53).

E assim defendeu seu contrato social:

uma forma de associação que defenda e proteja a pessoa e os bens de cada associado, de qualquer força comum, e pela qual cada um, unindo-se a todos, só obedece contudo a si mesmo, permanecendo assim tão livre quanto antes (ROUSSEAU, 1999, p. 70).

E continua:

Cada um de nós põe em comum sua pessoa e todo o seu poder sob a direção suprema da vontade geral, e recebemos, enquanto corpo, cada membro como parte indivisível do todo [...] Essa pessoa pública que se forma, desse modo, pela união de todas as outras, tomava antigamente o nome de cidade e, hoje, o de república ou de corpo político, o qual é chamado por seus membros de Estado (ROUSSEAU, 1999, p. 71). 
A América Inglesa do século XVIII ofereceu um ambiente receptivo para essas novas ideias surgidas na Europa, principalmente as de Locke, Montesquieu e Rousseau, servindo de inspiração para os ideais de liberdade dos colonos. Para Rousseau a soberania deve estar nas mãos do povo, através de um corpo político de cidadãos. Quando isso não acontece, o povo tem o direito de rebelar-se. Por tal fato sua obra teve grande influência na Revolução Francesa, principalmente no conceito da soberania do povo, mudando o direito da vontade do rei para a vontade geral do povo. Mas antes da Revolução Francesa, outro movimento veio abarcar a ideia de que o povo deve escolher seus representantes e a melhor forma de governo se faz por meio de uma convenção (ROUSSEAU, 1999).

As razões dessas ideias nascidas na Europa terem encontrado campo fértil em outro continente, culminando com o nascimento do Constitucionalismo moderno serão aqui apresentadas. Para se entender o contexto social que permitiu o surgimento do Constitucionalismo moderno na América Inglesa é necessária a compreensão dos fatos ocorridos desde o início das colônias. Pode se dizer que "diferentemente do que ocorria com as colônias dos demais países europeus, que exportavam suas vicissitudes: absolutismo, centralismo burocrático e intolerância religiosa", é notório que os colonos ingleses chegaram à América com uma razoável percepção de poder contido e institucionalizado (BARROSO, 2009, p. 15).

A primeira colônia data de 1606 , em um empreendimento privado criado por uma companhia de comércio internacional, seguida por outro empreendimento também privado em Massachusetts, buscando criar uma comunidade regida por seus valores religiosos. Para Maryland foram os católicos que sofriam perseguição religiosa. Na Pennsylvania chegaram os Quakers e na Georgia, súditos ingleses endividados que buscavam recomeçar a vida. É nítida a busca por uma nova vida no novo mundo (BARROSO, 2009).

Analisar-se-á aqui especificamente o caso da Massachusetts Bay Colony, berço da Revolução Americana e local onde a insatisfação tomou corpo e culminou em ataque físico às tropas britânicas, deflagrando a chamada American Revolution. Eles denominam a si próprios, até os dias de hoje como Liberty State (SMITH; WILSON, 1998).

O surgimento da Massachusetts Bay Colony é peculiar e simbólico, eis que por medo de perseguição por parte do governo britânico e em busca de liberdade religiosa, um grupo eclético de religiosos e pessoas comuns fretou um navio e partiu para colonizar o novo 
continente americano. O navio inglês batizado de Mayflower partiu do porto inglês de Plymouth levando estes separatistas puritanos, conhecidos mais tarde como Pilgrims (SMITH; WILSON, 1998).

Como exposto, o empreendimento colonial era privado e não recebia muita atenção por parte do governo Inglês; possuíam autonomia e se autogovernavam. O governador era designado por Londres, mas havia um corpo legislativo eleito localmente, assim como um judiciário independente (BARROSO, 2009).

Os colonos fundadores da Massachusetts Bay Colony chegaram à América em 21 de novembro de 1620 enfrentando situações extremamente difíceis do inverno. Acabaram se fixando em 26 de dezembro em um local ao qual chamaram Plymouth, o mesmo nome da cidade de onde partiram da Inglaterra, e ao chegarem já iniciaram entendimentos para a formação do que chamaram de Civil Body Politic (que seria um governo temporário), acabando por evoluir para a formação das bases do governo na chamada Plymouth Colony. Os colonos enfrentaram um rigoroso inverno, no qual metade deles sucumbiu de doenças e fome. Foi eleito pelos colonos, denominados Pilgrins, como primeiro governador, John Carver, um intelectual e líder religioso (FROTHINGHAM, 1916).

Novas correntes migratórias se seguiram à primeira, povoando a nova colônia, que agora se expandia pelo litoral e ingressava pelo interior. O direito aplicado era a base do Common Law Inglês, baseado na jurisprudência e nas normas criadas pela General Court, um corpo legislativo representativo, assim como por princípios religiosos que inspiraram a formação da comunidade. Na General Court, os homens livres e participantes da comunidade se reuniam para deliberar todos os assuntos de governo (FROTHINGHAM, 1916).

Percebe-se que o governo da Pilgrim Colony, como era chamado, era um governo de base política e religiosa. Não se pode entender o modelo inicial criado em Massachusetts como genuinamente democrático, pois o mesmo se parecia mais com uma pequena teocracia, mas era, sem dúvida alguma, um autogoverno democrático para a sua época (FROTHINGHAM, 1916). É necessário ressaltar que tudo isso aconteceu antes da citada Revolução Inglesa de 1688 e de John Locke.

Assim também entende Lawrence Friedman, em tradução livre:

O direito na colônia era basicamente o direito inglês em uma versão resumida. Muito do que pensamos sobre o direito inglês está relacionado aos problemas da 
aristocracia agrícola, mas não havia aristocracia agrícola na América, não nas colônias do nordeste.

Foi desenvolvido um tipo mais popular de direito neste lado do Atlântico. Popular não significa democrático (como nós entendemos a palavra hoje). Seria mais preciso chamar as colônias de pequenas teocracias. Mas elas foram populares em outros sentidos. As Courts eram fortemente presentes na vida das pequenas comunidades e lidavam com matérias relacionadas à vida de todos (FRIEDMAN, 2002, p. 28) ${ }^{2}$.

Com relação ao autogoverno pode ser afirmado:

As colônias possuíam um autogoverno na prática, se não em teoria. Este era o caso, por exemplo, em Massachusetts Bay. Em todos os aspectos, o controle Inglês era extremamente fraco. A Inglaterra era distante - um longo, árduo e perigoso caminho pelo mar; a Inglaterra não tinha uma real política colonial, não tinha nem a oportunidade nem habilidade, tampouco experiência em lidar com um império (FRIEDMAN, 2002, p. 23) ${ }^{3}$.

Com o tempo novos procedimentos foram criados. A General Court passou a ser formada por delegados eleitos pelas respectivas cidades. Ela podia decretar normas, que estariam em vigor apenas depois de aprovadas por duas legislaturas, o que garantia uma certa "rigidez" ao sistema legal. Observa-se aqui um sistema de governo através de um conselho, com participação dos homens livres e afetos às atividades religiosas, em uma democracia representativa (FROTHINGHAM, 1916).

Verifica-se aqui o surgimento de uma figura embrionária de democracia com bases religiosas, através da qual se desenvolvia o sistema legal e apontava as diretrizes para o autogoverno. O surgimento dessa ideia de comunidade e dessa nova forma de poder pela primeira vez nas Américas teve consequências diretas no nascimento do constitucionalismo moderno.

A forma como esse sistema de governo se desenvolveu na Pilgrim Colony, sendo na verdade um apêndice independente da administração incipiente que a Inglaterra possuía na

\footnotetext{
2 The law in colony, as we said, basically English, but a striped-down version. Much of what we think of as English law is really a law about the problems of the landed aristocracy. But there was no landed aristocracy in the colonies-certanly not in the northern colonies. It was a more popular, local kind of law that took hold on this side of Atlantic. Popular here doesn't not mean democratic (as we understand the word). It would be more accurate call the colonies little theocracies. But they were popular in the other senses. Courts were right of everybody's doorstep in these small communities. And they dealt with matters that concerned everybody, as we said (FRIEDMAN, 2002, p. 28).

3 The colonies were in effect self-governing - in practice, if not in theory. This was true, for example, of Massachusetts Bay. In all cases, English control was extremely weal. England was very far away - a long, arduous, and dangerous trip by water; and England had no real colonial policy, at least not to begin with. England had neither the the opportunity nor the skill nor the experience to manage an "empire" (FRIEDMAN, 2002, p. 23).
}

Revista Brasileira de Teoria Constitucional| e-ISSN: 2525-961X | Encontro Virtual | v. 6 | n. 2 | p. 01 - 21 | Jul/Dez. 2020. 
região é interessante e importante. Sobre as peculiaridades da aplicação das leis inglesas na América, assim escreveu Friedman, em tradução livre:

$\mathrm{O}$ direito inglês era o direito de uma sociedade antiga, com forte passado feudal e um elaborado e complexo sistema social, começando com o rei no topo e descendo da aristocracia e nobreza até o povo comum. A maioria da enlouquecedora complexidade técnica do direito inglês, fortemente formal e técnico, não era conhecida nas colônias; ela não era necessária. Os colonos utilizaram o que eles conheciam o que eles precisavam, ou melhor, do que eles se lembravam (FRIEDMAN, 2002, p. 24) ${ }^{4}$.

O governo oficial inglês foi estabelecido através da autorização real, pelo Rei Charles I somente em 1628, conhecido como Colony Charter, criando a Massachusetts Bay Company, similar a que criou a East India Company em 1599. Esta norma estabelecia supremacia a esta companhia, abaixo apenas do Rei e do Parlamento, mas os costumes e o autogoverno já tinham se consolidado naquela colônia (SMITH; WILSON, 1998).

Como uma forma de se evitar rupturas desnecessárias que poderiam gerar desordens, os colonos de Plymouth passaram então a fazer parte da General Court, que passou a funcionar paralelamente a Court of Assistants, formada pelo Governor, Deputy-Governor e Assistants. Era na verdade um corpo executivo e legislativo, e havia bastante autonomia para a administração e criação de leis a vigerem na colônia, se tornando válidas somente se não confrontassem leis da Inglaterra (FROTHINGHAM, 1916).

A Massachusetts Bay Colony, como era conhecida, teve o seu crescimento ao longo da costa e no sentido oeste. O desenvolvimento econômico acelerado e a expansão da colônia acabaram por desenvolver também a legislação, levando a adaptações e também a tornando mais sofisticada, mas sempre amoldada às peculiaridades locais. Como se pode ver, em tradução livre:

\begin{abstract}
A medida que as colônias cresciam, e conforme cidades como Boston se tornaram importantes portos e centros comerciais, o Direito foi se tornando mais sofisticado, mas ele nunca alcançou a altura (ou profundidade) do Direito inglês. Os colonos também se adaptaram, mudaram e criaram Direito, de forma a adaptá-lo às suas situações específicas, que eram, afinal de contas, muito diferentes das situações dos ingleses comuns. Também a ideologia dos colonos moldou seu Direito de maneira
\end{abstract}

\footnotetext{
${ }^{4}$ English law was the law of an older society, with a strong feudal past, and an elaborate and complex social system, starting with the king on top, and down through layers of aristocracy and gentry to the common folk. Most $f$ the maddening complexity of English law, highly crabbed and technical, was not only unknown in the colonies; it was also unnecessary. The colonists took what they knew, what they needed, what they remembered (FRIEDMAN, 2002, p. 24).
} 
importante. Os puritanos em Massachusetts, por exemplo, fizeram leis para se moldarem à ideia de uma sociedade do bem comum (goodly society).

Sabemos muito sobre o Direito em Massachusetts Bay no século XVII devido a arquivos sobreviventes. Sabemos muito sobre esta sociedade neste período também (FRIEDMAN, 2002, p. 25) ${ }^{5}$.

Massachusetts Bay Colony, que sempre possuiu bastante autonomia, passou a ficar ainda mais fora dos planos da Inglaterra, que estava extremamente envolvida na guerra colonial com a França, de 1754 a 1763, guerra esta em que um dos cenários se desenrolou nas colônias britânicas e francesas da América do Norte, tendo sido um dos teatros da Guerra dos Sete Anos. Isso gerou impacto na formação política dos que habitavam a colônia e permitiu o fortalecimento de um novo ideal de governo com bases populares (SMITH; WILSON, 1998).

Reflexos desse novo ideal vieram mudar a historia da América e da democracia. Bases teóricas para isso não faltavam, pois muitos dos que vieram para a colônia assim o fizeram não em busca de riqueza, mas em busca de liberdade para suas ideias e crenças; dentre eles um corpo também bastante intelectualizado que disseminou esse conhecimento às novas levas migratórias que chegavam. Vale lembrar que, por exemplo, a renomada Universidade de Harvard fora criada nesta colônia em 1636 como um centro de estudos políticos e administrativos (FROTHINGHAM, 1916).

\subsection{CONSEQUÊNCIAS DO ABUSO DO PODER DE TRIBUTAR}

Após a vitória sobre a França na Guerra dos Sete Anos, a Coroa Britânica instituiu um imposto sobre o selo, incidente sobre jornais, documentos e diversos outros itens, sob o fundamento de que as colônias deveriam contribuir para sua própria defesa. Houve forte reação e desobediência, "fundadas no argumento de que as colônias não haviam sido ouvidas e nem participavam do Parlamento, surgindo um dos slogans da revolução" que se avizinhava: "No taxation without representation" (BARROSO, 2009, p.15).

\footnotetext{
${ }^{5}$ As the colonies grew, and when such towns as Boston became important ports and commercial centers, the law became somewhat more sophisticated; but it never reached the Heights (or depths) of English law. The colonists also adapted, changed, and added to the law, in ways that suited their situation, which was, after all, very different from the situation of the ordinary English man or woman. Also the ideologies of the colonists shaped their laws in important ways. The Puritans in Massachusetts, for example, made law to suit their idea of a godly society (FRIEDMAN, 2002, p. 25).

We know a lot about the law of Massachusetts Bay in the seventeenth century from surviving records. We know a lot about society in that period, too (FRIEDMAN, 2002, p. 25).
} 
Em 1764, buscando mais controle e recursos, a autorização para a administração da colônia pela Massachusetts Bay Company foi revogada, sendo a administração da colônia transferida diretamente para a coroa. O objetivo da mudança de estratégia era o aumento da sua lucratividade, devido à imperiosa necessidade de recursos pelo governo inglês. Pela perspectiva do mercantilismo, para o Parlamento Britânico parecia razoável obrigar a colônia a ajudar a pagar os custos do império, que acumulava um déficit de cem milhões de libras, tributando ainda mais a colônia (SMITH; WILSON, 1998).

A empreitada era difícil, pois já havia se formado dentre os indivíduos a ideia de que eram cidadãos, eis que acostumados a elegerem seus representantes e a debaterem as questões políticas diretamente na General Court, - era um esboço de autogoverno e já fazia parte da vida da comunidade (SMITH; WILSON, 1998).

Criara-se um elaborado sistema administrativo e a observância às leis estava presente no dia-a-dia da comunidade. A ideia de separação de poderes ainda não estava presente, observa-se, em tradução livre:

\begin{abstract}
As comunidades eram pequenas, unidas e hierarquizadas. Alguns dos assentamentos eram pequenos o suficiente para que provavelmente todos conhecessem todo mundo. [...] Os principais cidadãos eram clérigos (masculinos) e pais de família. [...] Massachusetts desenvolveu seu próprio elaborado sistema de courts (significando, neste caso, espaços políticos governamentais e públicos). No topo havia a General Court, abaixo havia a Court of Assistants. A ideia de separação de poderes ainda não era encontrada nas colônias. As courts atuavam como um governo de amplo espectro de ação, e o Direito tinha um papel importante no dia a dia da comunidade (FRIEDMAN, 2002, p. 25) ${ }^{6}$.
\end{abstract}

Em busca de recursos e levando a cabo a política arrecadatória delineada pelo Parlamento Britânico, uma sequência de atos ligados à tributação foram editados, dentre os quais: Sugar Act: 1764; Stamp Act: 1765; Townshend Acts: 1767. A vida da colônia foi afetada diretamente com a taxação de produtos importados essenciais, como açúcar, melado de cana, vinho, chá, têxteis, café, papel, vidro, tintas e outros insumos. Todos os produtos, exceto o papel, eram taxados indiretamente, sendo o pagamento feito quando do ato de retirada dos produtos do navio, tendo repercussão imediata no preço final da mercadoria. Já o

\footnotetext{
${ }^{6}$ The communities were small, tight-knit, hierarchical. Some of the settlements were small enough so that probably everybody knew everybody else. [...] Massachusetts developed its own elaborate system of courts. At the top was the General Court, under it a Court of Assistants. [...] The idea of the separation of powers was not to be found in the colonies. The courts acted, as it were, as full-service government stations. And the law played an important role in the everyday life of the community (FRIEDMAN, 2002, p. 25).
} 
papel para uso comercial era taxado diretamente, sendo obrigatória a fixação de selo comprovando o pagamento do imposto em jornais e livros (SMITH; WILSON, 1998).

Os colonos, apesar de aceitarem a regulação do comércio (regulamentação e fiscalização) e o pagamento de impostos, questionavam a legitimidade do parlamento inglês em criar novos tributos ou aumentar as alíquotas de impostos sem a participação deles, colonos, os diretamente afetados pelas medidas e que sequer tinham oportunidade de participar dos debates e do processo de sua elaboração (FROTHINGHAM, 1916).

Diante do fim das hostilidades com a Franca e o restabelecimento da paz no Atlântico Norte, os comerciantes e mercadores entenderam ser este o momento de recuperação da economia em recessão e castigada por anos de conflito, restabelecendo o comércio marítimo (a principal atividade local) e a pesca. Os privilégios concedidos a West Indies Company e os novos tributos foram motivo de grande insatisfação (SMITH; WILSON, 1998).

Indivíduos de todas as classes sociais sentiram o golpe, inclusive advogados e políticos atuantes como John Adams e James Otis Jr., que desafiaram a autoridade do Parlamento Britânico questionando sua legitimidade para a edição de tais normas, visto que não havia representantes eleitos pelos americanos neste parlamento (FROTHINGHAM, 1916).

Pela principiologia criada após a Revolução Inglesa de 1688, qualquer lei do Parlamento que esteja “contrária à 'lei superior' deve ser declarada nula”, eis que contrária à common law, a “encarnação da razão”. E assim continua José Alfredo de Oliveira Baracho:

No ano de 1761 esse princípio começa fazer parte do conceito de Constituição, pelo que James Otis e John Adams defenderem as reivindicações de independência das Colônias da nova Inglaterra, proclamando que uma lei contrária à Constituição é nula (BARACHO, 2005, p. 151).

Ainda não havia uma Constituição escrita, mas a noção de hierarquia no ordenamento jurídico já estava presente, podendo-se afirmar que determinados preceitos e valores estavam tão cristalizados nos usos e costumas que acabavam tendo um valor jurídico intangível. 
Um grupo de colonos, após uma reunião, revoltados contra a cobrança do tributo relacionado ao Stamp Act, em sinal de protesto, no dia 14 de agosto de 1765, pendurou no alto de uma árvore a efígie simbolizando um conhecido Stamp Colector de nome Andrew Oliver. Durante todo o dia a efígie permaneceu pendurada no majestoso $\mathrm{elm}^{7}$, desafiando a presença de oficiais do governo, até que uma multidão, que a essa altura contava com milhares de indivíduos, a retirou e, triunfante, o jogou-a em uma fogueira. No dia seguinte Oliver renunciou a tarefa de distribuir os selos, que permaneceram no porto de Boston esperando quem tivesse coragem para fazê-lo (SMITH; WILSON, 1998).

No episódio acima descrito, os cidadãos de Boston conseguiram eficazmente obstar a aplicação de uma lei que entendiam ser ilegítima. Este ato deflagrou ações que se estenderam a Maryland, Rhode Island e Connecticut, forçando a renúncia dos respectivos coletores de impostos (SMITH; WILSON, 1998).

Nessas ações, além de uma ruptura moral com as instituições, o que houve foi o crescimento do sentimento de que a lei que os afetasse deveria ser feita por seus representantes. Para eles a legitimidade se daria apenas com a participação popular. Como se pode observar, em tradução livre:

Por suas ações, multidões afirmaram o direito de fazer sentir noções populares de justiça. Com efeito, os colonos, ao invés daquela lei, deveriam fazer leis em assembleias americanas, tribunais americanos e até nas ruas americanas (SMITH; WILSON, 1998, p. 24).

Em 1765, o líder da casa dos representantes do povo, a House of Representatives, de nome James Otis Jr. foi a New York a fim de organizar o Stamp Act Congress a fim de demonstrar no exterior a unificada oposição da colônia de Massachusetts ao Stamp Act, e acabou se espalhando pela América a já conhecida expressão "No taxation without representation" (SMITH; WILSON, 1998, p. 25).

Com o objetivo de causar mais clamor popular, popularizar o debate e trazer mais repercussão as discussões travadas na House of Representatives, o mesmo James Otis Jr. criou a visitor's gallery em 1766, a fim de permitir o acesso do publico em geral às sessões em que ocorriam calorosos debates contra os atos do Parlamento Britânico, permitindo assim, pela

\footnotetext{
${ }^{7}$ Essa árvore ficou conhecida como Liberty Tree e se tornou ponto de encontro para protestos e ações revolucionárias em Boston, até que foi derrubada por soldados ingleses no dia $1^{\circ}$ de setembro de 1775 (SMITH; WILSON, 1998).
} 
primeira vez, o contato da população com argumentos jurídico-políticos utilizados e aproveitando para acirrar mais ainda o sentimento geral anti-taxação. Em 1766 o Stamp Act foi finalmente revogado, tendo a população pendurado lanternas na liberty tree, criando uma "pirâmide iluminada" na noite de Boston (SMITH; WILSON, 1998).

O pragmatismo levou o Parlamento Britânico a perceber a pouca praticidade e o problema causado pelo Stamp Act e resolveu agir de outra forma para atingir seu objetivo arrecadatório, aprovando Townshend Act em 1767. Este era o mais nefasto de todos, pois atingia todos os produtos importados pela colônia e vinha acompanhado de uma sistemática arrecadatória bastante agressiva, impondo a fiscalização de toda a mercadoria no desembarque e o imediato recolhimento do imposto (SMITH; WILSON, 1998).

A cada dia a insatisfação da colônia contra o domínio inglês piorava. Logo no inicio de 1768 a General Court se reuniu e produziu um documento contrario ao Townshend Act, enviando-o a outras assembleias das demais colônias Americanas, conclamando união contra tal norma. Quando a noticia chegou à Inglaterra, o Rei George III exigiu imediatamente a retratação. Tal exigência foi posta em deliberação e recebeu 92 votos contrários e 17 votos favoráveis a retratação. Diante da recusa, o governador Francis Bernard dissolveu a General Court em outubro de 1768, pedindo ao Rei, em seguida, o envio de mil homens do exercito inglês para Boston (SMITH; WILSON, 1998).

Os soldados britânicos foram enviados a Boston a fim de constranger os colonos, causando forte sentimento indignação. Com o intuito de humilhar os colonos, o Governador mandou instalar parte das tropas no prédio conhecido como Old State House, onde funcionava a House of Representatives, ou seja, o local onde tinham assento os representantes do povo. Mesmo com a proibição, os membros da House of Representatives continuaram a se reunir, agora às escondidas e em outro local (SMITH; WILSON, 1998).

Como era previsível, a tensão culminou, em 5 de marco de 1770, com o episodio chamado Boston Massacre, no qual soldados ingleses abriram fogo contra uma multidão de colonos que os insultava, atirava pedras e bolas de neve. Os moradores da cidade exigiam a imediata remoção das tropas, enquanto Samuel Adams, um dos mais ativos políticos 
conclamou: "O poder militar é criado pelas comunidades civis para proteger e não governálas"8 Tradução livre (SMITH; WILSON, 1998, p. 60).

Este episódio, apesar de ter sido um dentre muitos outros confrontos entre colonos e a tropa, teve o componente extra das baixas entre os civis, e passou a ser um objeto de propaganda por parte dos Patriots $^{9}$, que divulgaram o episódio para fortalecer os princípios fundamentais da revolução que conclamavam (SMITH; WILSON, 1998).

Em 1773 o Tea Act deu à Companhia das Índias Ocidentais o monopólio da distribuição de chá no mercado americano (BARROSO, 2009). Em resposta a este ato considerado ofensivo, alguns cidadãos de Boston liderados por Samuel Adams tomaram de assalto, em sinal de protesto, um navio de carga da India East Company no porto de Boston, jogando sua carga ao mar. A essa altura, a situação já dava sinais de que ia sair do controle e alguns cidadãos, entre eles membros da House of Representatives, elegeram delegados para o primeiro Continental Congress e também iniciaram a criação do Povincial Congress, com representantes de todas as cidades da colônia de Massachusetts (SMITH; WILSON, 1998).

Quando colonos armados atacaram as tropas Britânicas em Lexington e Concord em 19 de Abril de 1775 a chamada The Revolutionary War começara (SMITH; WILSON, 1998). A notícia dos confrontos se espalhou pela colônia e fazendeiros, caçadores e homens comuns abandonaram seus afazeres, pegaram suas armas e se dirigiram à capital para ver o que estava ocorrendo. Ao chegarem, uniram-se a outros patriots que estavam se organizando e formando milícias integradas, em parte, por ex-oficiais do exército britânico de origem americana para enfrentar os britânicos que em breve desembarcariam vindos do Canadá (FROTHINGHAM, 1916). A tensão se elevou e o que se seguiu foi a primeira grande batalha da Guerra Revolucionária,- Bunker Hill (SMITH e WILSON, 1998).

Seguidamente, uma após outra, cada uma das até então colônias, conseguia expulsar de seus limites territoriais os seus mandatários britânicos. O vazio de poder fora suprido de pronto e, em cada uma delas, as respectivas assembleias se reuniram criando seu próprio governo. As assembleias já eram representativas, eis que eleitas pelo voto, sendo a base do poder popular. Há que se enfatizar que, obviamente, o sistema democrático daquela época tinha grandes diferenças se comparado com o que se entende hoje por democracia, pois

\footnotetext{
${ }^{8}$ Military power is created by civil communities to protect not to govern them.

${ }^{9}$ Nome dado àqueles que se engajaram à luta contra o domínio britânico.
} 
apenas uma parcela da população votava, deixando de lado, por exemplo, mulheres e escravos, mas há que se entender a grande mudança de paradigma, pois pela primeira vez no mundo ocidental não havia nenhuma distinção entre homens livres (FROTHINGHAM, 1916).

\section{O CONSTITUCIONALISMO MODERNO}

O pensamento liberal desenvolvido na Europa sob a influência de John Locke, que impregnava o sistema britânico desde o pós-revolução inglesa de 1689 e as ideias liberais estavam a influenciar corpo político e tinham agora a chance de serem colocadas em prática. Dentre elas, especificamente as teorias de John Locke, trabalhadas na perspectiva dos direitos naturais - vida, liberdade e bens, a que chamava de propriedade, serviram sobremaneira de inspiração à revolução e posterior desenvolvimento do constitucionalismo americano. Suas bases conceituais permitiram aos colonos justificar a revolução lançando a ideia de governo com o consentimento dos governados (LOCKE, 1978).

Dessa forma pode-se afirmar que

estavam prontas as bases do constitucionalismo, pois a partir da independência em 1776, e da adoção de constituições rígidas nas treze colônias americanas, surgiram na América do Norte os primeiros elementos do constitucionalismo moderno (BARACHO, 2005, p. 151).

Ato contínuo ao início da Revolução Americana, cada um dos corpos legislativos de cada uma das ex-colônias se reuniu para deliberar sobre as questões de governo. Dos debates surgiu a ideia de criação de governos com prazo de duração prefixado e eleitos através do voto popular, ou seja, repúblicas. Inclusive muitas adotaram a denominação de Commonwealth que, além da noção de comunidade, também teria embutido neste conceito um sentido de corpo social. Um corpo social autônomo governado por seu povo, sendo utilizado por vezes como sinônimo de república (FROTHINGHAM, 1916).

A república era vista como sendo a única forma de governo capaz de repelir a tirania. Mas ela apenas não bastava, seria necessário o estabelecimento de limites de ação deste governo, e também, por norma escrita, disciplinar sua escolha pelo povo. Havia, pois, a necessidade de uma Constituição, e esta deveria ser uma lei, superior às demais e de forma escrita (DALLARI, 1998). 
Conforme disponibilizado nos arquivos da Yale Law School, é possível observar os primeiros textos constitucionais americanos, que na verdade são os primeiros textos constitucionais escritos e representam o início do que se convencionou chamar de constitucionalismo moderno. A primeira foi a Constituição de New Hampshire, datada de 05 de janeiro de 1776, antes, pois, da Carta de Direitos da Virgínia e da própria declaração conjunta de independência, promulgada por representantes das ex-colônias em 04 de julho de 1776 (New Hampshire, 1776).

Já em 26 de março de 1776 surgiu o texto constitucional de South Carolina, já tratando da eleição de presidente para esta então república, bem como a definição do corpo legislativo (General Assembly e Legislative Council) e sua periódica eleição (South Carolina, 1776).

Seguiu-se a Constituição de Virginia somada à Virginia Declaration of Rights de 29 junho de 1776, agora já com um aspecto de constituição na acepção moderna, trazendo uma declaração de direitos dos cidadãos e tratando do funcionamento do Estado (VIRGINIA, 1776).

Na sua SEC. 6. trata da limitação ao poder estatal à tributação, em tradução livre:

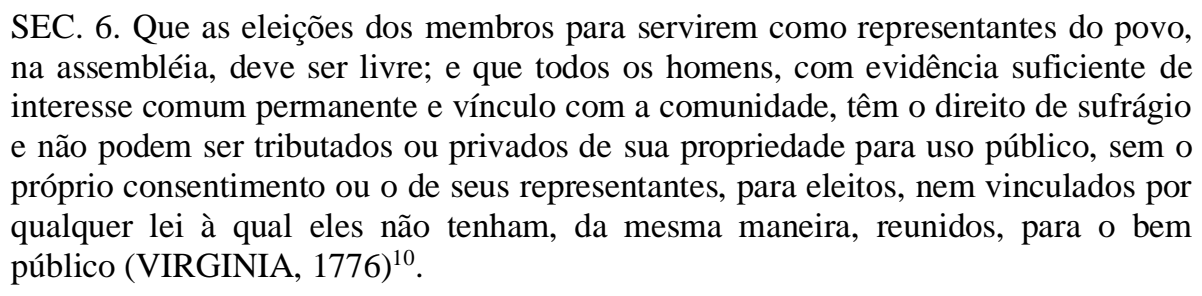

Seguiram-se outras constituições, como a de New Jersey, Pennsylvania, Maryland, North Carolina, Georgia, New York, Vermont, Connecticut e Massachusetts.

A chamada Constitution of the Commonwealth of Massachusetts merece o destaque para o fato de ser a mais antiga Constituição escrita do mundo ainda em vigor, conforme consigna Jorge Miranda (2003, p.144). Data de 1780 tendo, por óbvio, sofrido emendas ao longo dos anos a fim de adequá-la aos tempos atuais, mas tendo a maior parte de seu conteúdo

\footnotetext{
${ }^{10}$ SEC. 6. That elections of members to serve as representatives of the people, in assembly, ought to be free; and that all men, having sufficient evidence of permanent common interest with, and attachment to, the community, have the right of suffrage, and cannot be taxed or deprived of their property for public uses, without their own consent, or that of their representives so elected, nor bound by any law to which they have not, in like manner, assembled, for the public good.
} 
intacto. É interessante observar também seu cuidado com relação à limitação do poder de tributar no seu Artigo XXIII, em tradução livre: "Nenhum subsídio, encargo, imposto, imposição ou taxa deve ser estabelecido, fixado, estabelecido ou cobrado, sob qualquer pretexto, sem o consentimento do povo ou de seus representantes na legislatura" (MASSACHUSETTS, 1780), fazendo lembrar o antigo mote que antecedeu a Revolução Americana: "No taxation without representation" (BARROSO, 2009, p.15).

A historia de Massachusetts se confunde em muitos aspectos com a própria história da criação dos Estados Unidos da América e do constitucionalismo escrito, além de ter sido o berço da insatisfação pela excessiva tributação.

\section{CONCLUSÃO}

Ao se conectar fatos históricos que ligaram uma comunidade a um fim comum e indiretamente fazendo nascer uma Constituição, tem-se pelo menos a ideia de como evoluiu tal processo, permitindo a captação da inspiração que motivou a Revolução Americana e, consequentemente o constitucionalismo moderno. Fato é que havia um interesse à priori pela separação, mas havia um limite bem claro ao que era tolerável com relação à intervenção e à tributação.

Ao se fazer uma leitura atual do que se passou e a motivação ao se criar limites à ação do Estado sobre os indivíduos, verifica-se que estão presentes elementos de vanguarda para sua época, sendo nítida a inovação até então sem precedentes no mundo jurídico-político. Conforme se pode verificar, o Constitucionalismo escrito foi mais que um movimento que buscava simplesmente conferir Constituições aos Estados; buscava a proteção de interesses da sociedade.

O Constitucionalismo moderno surgido na América Inglesa no final do século XVIII representou uma mudança paradigmática que alterou sobremaneira as instituições jurídicas no mundo moderno. A compreensão dos objetivos que nortearam a criação destes documentos constitucionais mostra o aparecimento do poder social como um vínculo que une o povo a um fim comum, além de limites claros ao exercício do poder, dentre eles o poder de tributar.

O Constitucionalismo escrito não está dissociado de suas causas, principalmente as tributárias, e não se pode de forma alguma relegar a um segundo plano o que ocorrera na 
América Inglesa nos fins do século XVIII. Foi um movimento complexo e que trouxe elementos de vanguarda em sua época, merecendo estudo no que concerne às mudanças estruturais causadas no Estado.

A percepção do Direito como um sistema integrado por fatores políticos, sociais e econômicos leva à necessidade de se compreender também a sua dimensão história, o que o torna mais vivo e instigante.

\section{REFERÊNCIAS}

BARACHO, José Alfredo de Oliveira. Teoria geral da justiça constitucional. Revista Forense, Rio de Janeiro, v.101, n.380, p.149-177, jul./ago. 2005.

BLAUSTEIN, Albert P. A Constituição dos EUA: O produto de exportação mais importante do país. Constitucionalismo e Democracias Emergentes. Revista Eletrônica do Departamento de Estado dos EUA, Washington, v.9, n.1, março 2004. Disponível em: https://www.do.ektu.kz/COM/INFOUSA/CD2/docs/Ejournals/Portugese/Government/Constit utionalism\%20and\%20Emerging\%20Democracies.pdf. Acesso em: 15 ago. 2020.

DALLARI, Dalmo de Abreu. Elementos de teoria geral do estado. 20.ed. São Paulo: Saraiva, 1998.

FRIEDMAN, Lawrence Meir. Law in America: A short story. New York: The Modern Library, 2002.

FROTHINGHAM, Louis Adams. A brief history of the Constitution and Government of Massachusetts. Cambridge: Harvard University, 1916.

KUHN, Thomas S. A estrutura das revoluções científicas. Tradução de Beatriz Vianna Boeira e Nelson Boeira. 5. ed. São Paulo: Perspectiva, 2000.

LOCKE, John. Segundo Tratado Sobre Governo. In: Os Pensadores. São Paulo: Abril Cultural, 1978.

MANCUSO, Rodolfo de Camargo. Interesse difuso: conceito e legitimação para agir. 6. ed. São Paulo: Revista dos Tribunais, 2004. 
MASSACHUSETTS (USA). Massachusetts Constitution 1780. Disponível em: https://malegislature.gov/Laws/Constitution\#preamble. Acesso em: 20 out. 2019.

MIRANDA, Jorge. Manual de direito constitucional. 3.ed. Lisboa: Coimbra, 2000. T. IV.

MIRANDA, Jorge. Manual de direito constitucional. 7.ed. Lisboa: Coimbra, 2003. T. I.

MONTESQUIEU, Charles Luiz de Secondat. Do espírito das leis. São Paulo: Nova Cultural, 1997.

NEW HAMSHIRE (USA). The Constitution of New Hampshire; January, 1776. Disponível em: http://www.yale.edu/lawweb/avalon/states/va05.htm. Acesso em: 20 out. 2019.

ROUSSEAU, Jean-Jacques. Vida e obra. São Paulo: Nova Cultural, 1999. V.I

SOUTH CAROLINA (USA); Constitution of South Carolina; March 26, 1776. Disponível em: https://avalon.law.yale.edu/18th century/sc01.asp. Acesso em: 30 out 2019.

SMITH, Barbara Clark; WILSON, Susan. Boston and the American Revolution. Washington, D.C: Division of Publications National Park Service, 1998.

TERUYA, T. K ; GOMES, I. O. ; LUZ, M. G. E. ; CARVALHO, Aline Monique . As contribuições de John Locke no pensamento contemporâneo. In: IX Jornada do HISTEDBR, 2010, Belém. O nacional e o local na história da educação. Campinas: HISTEDBR- FE/UNICAMP, 2010. v. 1. p. 1-18.

VIRGINIA (USA). The Constitution of Virginia; June 29, 1776. Disponível em: https://www.law.gmu.edu/assets/files/academics/founders/VA-Constitution.pdf. Acesso em: 20 out. 2019. 